\title{
ФИНАНСОВАЯ ГРАММОТНОСТЬ И ВЫСШЕЕ ОБРАЗОВАНИЕ: ОПЫТ ВНЕДРЕНИЯ, ПРОБЛЕМЫ И ПЕРСПЕКТИВЫ
}

\section{FINANCIAL LITERACY AND HIGHER EDUCATION: IMPLEMENTATION EXPERIENCE, CHALLENGES AND PROSPECTS}

\section{O. Belyaeva \\ A. Nekrasova}

Summary: This article analyzes the financial literacy among the students, carried out of the method of questioning at the Pacific National University. The result of this work should be considered an illustration of the need to implement comprehensive measures to improve financial literacy among the students of the university.

Keywords: financial literacy, students, economic competencies, practices of introducing financial literacy.

\author{
Беляева Олеся Николаевна \\ Старший преподаватель, ФГБОУ ВО «Тихоокеанский \\ государственный университет», Хабаровск \\ 003835@pnu.edu.ru \\ Некрасова Александра Игоревна \\ Преподаватель, ФГБОУ ВО «Тихоокеанский \\ государственный университет», Хабаровск \\ 010290@pnu.edu.ru
}

Аннотация: В данной статье проведен анализ финансовой грамотности студентов, проведенный методом анкетирования на базе Тихоокеанского Государственного Университета. Результатом данной работы следует считать иллюстрирование необходимости реализации комплексных мер по повышению финансовой грамотности среди студентов вузов.

Ключевые слова: финансовая грамотность, студенты, экономические компетенции, практики внедрения финансовой грамотности.
Ц ель данной работы состоит в том, что содержательная часть программ подготовки студентов по финансовой грамотности должна быть направлена на формирование устойчивых экономических компетенций с учетом будущей профессиональной деятельности выпускников. Значительное внимание необходимо уделять мотивационной и деятельностной стороне формирования экономических компетенций, как основополагающей цели повышения финансово-экономической грамотности, а не формированию экономического мышления на понятийном уровне, на уровне представлений о специфике экономических процессов, законов и закономерностей. При этом особо важным является принцип актуальности, простоты и доходчивости подаваемой информации, ее связи с реальной жизнью и возрастными интересами обучаемых.

В данной статье использовались следующие методы: анализ литературы, исследовательских работ, официальных документов позволили создать список информационных источников, содержащих практический и теоретический материал, способствующий изучению вопросов формирования экономических компетентностей и повышению уровня финансово-экономической грамотности студентов.

\section{Результаты.}

В ходе данной работы был проведен анализ уровня финансовой грамотности среди студентов старших курсов Тихоокеанского Государственного Университета. В результате анализа полученных данных был обнаружен удовлетворительный объективный и субъективный уровень финансовой осведомленности среди молодежи. Данная работа показывает, что студенты ТОГУ все же не в полной мере обладают самыми высокими компетенциями в вопросах финансах. На основании этого можно сделать предположение о том, что данные студенты после окончания учебного заведения будут испытывать некоторые трудности с грамотным управлением своими финансовыми ресурсами, и, как следствие, с определением своего самостоятельного социально-экономического положения. Результатом данной работы следует считать иллюстрирование необходимости реализации комплексных мер по повышению финансовой грамотности среди студентов Хабаровска. В будущих работах хотелось бы более подробно остановиться на конкретных аспектах финансовой грамотности и посмотреть их связь с уже известными нам зависимостями, кроме того, хотелось бы расширить количество университетов для того, чтобы включить в выборку, к примеру, медицинские и военные ВУЗы. И как один из наиболее интересных вариантов - провести обучение из текущей выборки людей, которые заинтересованы в нем, и сравнить их результаты до и после обучения.

\section{Введение}

Высшая школа - это очень важный момент для учащихся в развитии навыков личных финансов, которые потребуются им для самостоятельной жизни во взрослом возрасте. Освоение основ финансовой грамотности 
- лучший способ настроить их на жизнь, полную здоровых финансовых привычек, обеспечивающих их успех в будущем[3, с.222; 4, с.112].

Студенты этого возраста могут быть уже знакомы с концепциями управления деньгами, такими как кредит или займы, и с тем, как ими пользоваться. Но теперь пришло время копнуть глубже и рассказать о реальных применениях финансовых решений.

Необходимость внедрения уроков финансовой грамотности в вузе обусловлена тем, что современные дети достаточно активно самостоятельно покупают товары, пользуются пластиковыми картами и мобильными приложениями. То есть, они с раннего возраста оперируют денежными знаками и являются активными участниками торгово-финансовых взаимоотношений, что требует от них определенного уровня финансовой грамотности. Главной задачей ведения обучения финансовой грамотности, конечно же, является стремление остановить развитие безответственного отношения к денежным операциям в целом [7, с.18]. Ведь большая часть взрослого населения нашей страны, к сожалению, до сих пор финансово безграмотна и ничем не защищена в случае непредвиденных обстоятельств или потери работы. Во многих семьях не ведутся учеты расхода и дохода. И это печально сказывается на развитии экономики в сфере потребления.

Перед педагогом профессионального обучения ставится принципиально новая общекультурная задача: целенаправленно готовить юных граждан не только к труду и познанию, но и полноценному вступлению в противоречивые социально-экономические отношения в стране в условиях развития рыночного типа экономики. Повышение финансово-экономической грамотности возможно через формирование экономических компетенций [1, с.87].

Проблемы экономической подготовки в системе среднего и высшего профессионального образования рассмотрены в работах Л.Л. Любимова, А.А. Мицкевич, И.В. Липсица, В.С. Автономова и др. Интересны разработки в направлении формирования экономических компетенций студентов не экономических профилей К.А. Баранникова, К.И. Старостиной, О.Г. Назаровой, Н.Е. Поповой, А.В. Боранукова, А.Ф. Казаковой[2, с.3].

При создании и методическом наполнении программы у студентов не экономических специальностей педагог-практик сталкивается с проблемой теоретической неразработанности вопроса, ограниченным перечнем официальных документов, дающим возможность грамотно изменить направление обучения в соответствии с требованием времени, недостатком практических материалов. Анализ литературы, исследовательских работ, официальных документов позволили создать список информационных источников, содержащих практический и теоретический материал, способствующий изучению вопросов формирования экономических компетентностей и повышению уровня финансово-экономической грамотности студентов.

В Тихоокеанском государственном университете состоялся круглый стол «Финансовая грамотность и высшее образование: опыт внедрения, проблемы, перспективы». в рамках мониторингового визита представителей Федерального сетевого методического центра (ФСМЦ) экономического факультета МГУ имени М.В. Ломоносова в г.Хабаровск. На круглый стол приглашены представители Правительства Хабаровского края, Министерства финансов Хабаровского края, Отделения по Хабаровскому краю Дальневосточного главного управления Центрального банка РФ, руководства и профессорско-преподавательского состава образовательных организаций Хабаровского края и ЕАО, а также пресса. Рассматривались следующие вопросы для обсуждения:

- практики внедрения финансовой грамотности в высшем образовании: опыт, проблемы, результаты;

- универсальная компетенция УК-10 (экономическая культура, в том числе финансовая грамотность) и специфика ее формирования у студентов вузов определенной направленности (профиля) обучения;

- вопросы взаимодействия на федеральном и региональном уровнях.

В рамках круглого стола рассматривались следующие основные концепции:

- Интернет-ресурсы для обучения финансовой грамотности учащихся.

- Приложения и игры для обучения финансовой грамотности студентов.

- Советы экспертов по обучению финансовой грамотности обучающихся.

Также в рамках мониторингового визита представителей ФСМЦ в ТОГУ было проведено тестирование и интервьюирование студентов неэкономических направлений подготовки (специальностей) и преподавателей университета, успешно завершивших обучение по программе повышения квалификации «Разработка и реализация рабочих программ дисциплин (модулей) по финансовой грамотности для студентов образовательных организаций высшего образования».

Учащимся старших классов, а также студентам вузов необходимо знать о своих финансовых возможностях для получения высшего образования и возможностях будущей карьеры. Это включает в себя варианты финансирования и то, как выбрать карьеру, исходя из ожида- 
ний качества жизни (надеюсь, при жизни по средствам) $[8$, c.78].

В данной статье собраны воедино важные финансовые концепции, которые обучающиеся должны усвоить, прежде чем получить высшее образование и вступить в реальный мир - будь то высшее образование или поиск работы. Кроме того, мы включили отличные идеи от преподавателей, знакомых с преподаванием личных финансов для учащихся.

Концепция № 1: Составление бюджета для достижения финансовых целей

Подростки уже должны знать о доходах и расходах. Пришло время им научиться контролировать приток и отток денег, создавая и придерживаясь плана расходов.

Это особенно полезно, учитывая, что многие студенты могут самостоятельно зарабатывать деньги, будь то летняя работа или оплачиваемая стажировка. Здесь важно отметить следующие ключевые моменты:

- Начальный бюджет. Бюджетирование - это определение приоритетов доходов и расходов. Доход должен равняться расходам, причем каждый доллар предназначен для определенной цели, включая сбережения. Распределяя каждый доллар по расходам, вы будете знать, на что и как тратятся ваши деньги.

- Экономия. Откладывание денег сейчас позволяет нам иметь деньги, которые мы можем потратить позже. Делая вклад на сберегательный счет, например, на чрезвычайный фонд, вы можете достичь краткосрочных и долгосрочных финансовых целей.

Концепция № 2: Потребительские навыки основаны на осознанных решениях

Способность принимать разумные решения о том, где и как тратить деньги, - мощный инструмент. Подростки могут практиковать свои навыки принятия решений о потребителях с помощью реальных сценариев, например, совершая разумные покупки, сравнивая покупки. Здесь важно отметить следующий ключевой момент:

- Сравнение покупок. Получите максимальную отдачу от вложенных средств, совершив покупки перед покупкой. Тратя деньги с умом, вы сможете сбалансировать количество и качество каждой покупки, чтобы получить максимальную выгоду.

Концепция № 3: Понять риски кредитов и займов

Студентам, возможно, скоро понадобится кредитная карта или студенческая ссуда.
Прежде чем заключить соглашение о вероятности накопления долга, студенты должны знать о рисках различных типов заимствований, включая как кредитные, так и ссуды [10].

Студенты также должны знать о способах минимизировать риск, например о приобретении страховки. Хотя они, вероятно, не несут ответственности за приобретение страховки прямо сейчас, они будут участвовать в будущем, когда будут владеть автомобилем или снимать квартиру. Здесь следующие ключевые моменты:

- Долг. Кредиты и займы могут стать причиной возникновения долгов. Следует избегать долга, поскольку он учитывается в общем состоянии заемщика.

- Риск. Займы в кредит сопряжены с риском. На заемные деньги начисляются проценты, в результате чего каждая покупка становится дороже, чем первоначальные расходы. Самый большой риск, связанный с кредитом, заключается в пропуске платежа, что может повлиять на кредитоспособность заемщика и потенциально привести к повторному вступлению во владение или потере права выкупа.

- Страхование. Есть способы снизить риск, например, приобретя страховку, которая возвращает страхователю выплаты в случае обоснованного требования. Страхование может покрывать здоровье и имущество, например автомобили и дома.

Кониепция № 4: Воспользуйтесь преимуществами кредитов и займов.

Есть такая вещь, как хороший кредит, который позволяет заемщику совершать покупки, способствующие накоплению богатства. Например, возможность оплатить учебу в колледже с помощью студенческой ссуды или купить дом с помощью жилищной ссуды - это способы, которыми кредит позволяет заемщикам инвестировать в долгосрочные выборы.

Обучающиеся должны научиться эффективно управлять кредитами и займами, чтобы поддерживать здоровую кредитную историю, повышать кредитный рейтинг и создавать богатство. Ключевые моменты в этом направлении:

- Кредит. Кредит - это инструмент, который может быть хорошим или плохим. Задолженность по кредитной карте обычно плохая, поскольку по ней взимаются проценты за покупки, которые заемщик не может себе позволить. Кредитная задолженность может быть хорошей (но не всегда), если студенческие ссуды позволяют заемщику финансировать образование в надежде получить более высокий доход [11].

- Создание богатства. Взяв кредит или ссуды для 
инвестирования в финансовые цели, такие как образование или домовладение, заемщик может начать наращивать богатство, выплачивая долги. Сбережения и инвестирование - лучшие стратегии для создания богатства.

Концепчия № 5: Образование и выбор профессии влияют на качество жизни

После окончания средней школы у подростков есть выбор: продолжить образование или устроиться на работу. Подростки должны будут представить себе жизнь, которую они хотят вести, и сделать выбор, основываясь на понимании взаимосвязи между образованием, карьерой и потенциалом заработка.

Понимая возможности образования и карьерного роста, студент может принять осознанное решение о жизненно важных выборах, начиная с вуза, в котором он учится, и заканчивая суммой, которую он берет в качестве студенческой ссуды. Здесь ключевыми моментами могут стать:

- Потенциал заработка. Потенциал дохода в течение всей жизни - это то, сколько вы можете рассчитывать на максимальную зарплату в высшей области своей области или профессии. Сделайте шаги в образовании и карьере, необходимые для достижения профессиональных и финансовых целей.

Лучшие ресурсы для обучения финансовой грамотности старшеклассников и студентов, включая некоммерческие организации и государственные учреждения.

Программа финансового планирования средней школы Национального фонда финансового образования (NEFE) предназначена для студентов, преподавателей и родителей. Предоставляет учебный план, планы уроков, раздаточные материалы и оценки успеваемости.

Программа по финансовому планированию для старшеклассников и студентов - это программа повышения финансовой грамотности, основанная на принципах личных финансов, но имеющая отношение к жизни подростков. Программа предоставляет учебный план, планы уроков и материалы для личного обучения и лучше всего подходит для преподавателей, которые планируют преподавать в вузе, на семинаре или индивидуально.

Данный вид деятельности обеспечивает преподавателей учебными программами по финансовой грамотности для учащихся старших классов. Программа разработана так, чтобы быть строгой и увлекательной для учащихся, с высококачественными материалами, такими как планы уроков и презентации для преподавателей. Планы уроков рекламируются как доступные для любой аудитории, независимо от возраста и социально-экономического положения.

Программа повышения финансовой грамотности для студентов экономического факультета содержит колоссальные 14 планов уроков и дополнительные рабочие листы. Этого материала хватит на полный семестр курса по личным финансам. Он поставляется с руководством для преподавателя, руководством для учащихся и большим количеством презентационных материалов [5, с.46].

Онлайн-курсы являются самостоятельными и позволяют пользователю изучать темы финансовой грамотности на каждом этапе жизни. Для старшеклассников есть классные ресурсы, которые отлично подходят для преподавателей: Федеральная корпорация по страхованию вкладов (FDIC) «Money Smart for Young People» разработана для педагогов и учащихся.

Серия «Умные деньги для молодежи», выпускаемая FDIC, содержит четыре бесплатные учебные программы с учетом возраста для преподавателей. Учебная программа, соответствующая средней школе, включает планы уроков, руководства и ресурсы, которые достаточно просты для использования как педагогами, так и родителями. Материалы можно интегрировать в уже существующие школьные курсы, такие как английский или математика.

Обучать финансовой грамотности можно через искусство. Студенты ТОГУ, обучающиеся по разным направлениям, на протяжении всего курса вдохновляются на развитие критического мышления, решения проблем и ответственного принятия решений. На занятиях используются вышеперечисленные виды программ, где студенты понимают, как рассчитывать налог с продаж, процентные ставки и предлагаемые скидки, чтобы они могли принимать обоснованные решения о своих выступлениях. Это позволяет студентам узнать о реальных сценариях из области искусства, которые могут быть применены в широком диапазоне областей, таких как покупка автомобиля, дома, продуктов, мобильного телефона, обуви и одежды. Вдобавок они начнут включать некоторые навыки, которым они учатся сейчас, в свою повседневную практику, чтобы со временем совершенствовать их методом проб и ошибок, пока не стало слишком поздно. Существуют некоторые ошибки, которые допускают многие образовательные программы при обучении студентов финансовой грамотности: студенты не являются будущими участниками финансов и потребления [6, с.14]. В одном учебнике в моем классе постоянно обсуждали, как подготовить студентов к принятию финансовых решений. Фактически, студенты были в игре с тех пор, как впервые познакомились со СМИ. Их ценности, отношение и привычки в отношении денег формировались с детства. К сожалению, сообщение обычно 
звучит так: «тратьте сейчас и беспокойтесь о том, чтобы когда-нибудь сэкономить».

Финансовые примеры из реального мира должны быть взяты из реального мира старшеклассников, а не взрослых. Часто педагоги учат финансовой грамотности, заставляя детей делать вид, что они покупают дом, притворяться, что у них есть семья, и разыгрывать другие примеры, с которыми они, вероятно, столкнутся в будущем. Проблема в том, что для большинства старшеклассников эти примеры все еще являются теоретическими, поэтому они остаются абстрактными и не приживаются. Использование небольших примеров, которые ближе к подростковому опыту - финансирование автомобиля или другого желаемого продукта, решение, стоит ли того, чтобы устроиться на работу после школы, даже планирование бюджета на выпускной бал - имеют большое значение для достижения цели, реально для детей, давая им прочную основу для развития.

Необходимо сосредоточиться на том, чтобы научить студентов, почему они должны заботиться о своих финансах, а не читать лекции о том, как они должны с ними обращаться. Программа, которая фокусируется на «почему», будет мотивировать студентов оставаться вовлеченными в принятие каждого решения на протяжении всей своей финансовой жизни.

Необходимость внедрения уроков финансовой грамотности надо начинать на уровне старшей школы, продолжать обучаться этому в высших учебных заведениях и практически учиться этому на протяжении всей жизни.

Нужно сосредоточиться на личных приоритетах. Предложить учащимся понять, что для них действительно важно и что делает их счастливыми, а затем исследовать финансовые решения, которые отражают эту иерархию.

Связать их финансы и их реальную жизнь, думая о качестве жизни. Как только учащиеся определят, что для них важно, будет легче выявить и отсеять любые траты, которые не соответствуют их личным приоритетам.

Обдумать и персонализировать долгосрочные результаты. Помочь студентам прочувствовать свое будущее и свои приоритеты, чтобы они могли отказаться от сбережений для того образа жизни, который им больше всего нравится.

\section{Заключение.}

Финансовая грамотность определяется через три составляющих ее компонента - это знания, установки и навыки индивида. После экономических и социальных трансформаций 90-х годов население России столкнулось с проблемой массовой финансовой безграмотности, что негативно сказывалось на благосостоянии и домохозяйств и экономики страны в целом. На данный момент в мировой исследовательской практике, так же как и в России, наблюдается объективно невысокий уровень финансовой грамотности (низки показатели всех трех компонентов - знаний, навыков и установок), с чем активно пытаются справиться государства в сотрудничестве с (не)правительственными организациями: реализуется множество различных проектов, создаются новые формирования и умения. Субъективный уровень взрослого населения также невысок, чего нельзя сказать о молодежи - их оценки находятся на достаточно высоком уровне, что определённо не может служить мотивацией к самостоятельному изучению материала - отсюда значительный разрыв между предоставляемым набором источников для повышения финансовой грамотности в свободном доступе и низким ее уровнем у граждан [9, с.98]. Разницу по возрасту в субъективных оценках можно объяснить двумя причинами: во-первых, у студентов идет непрерывное параллельное получение знаний в университетах, что может создавать ложный фон хорошей информированности, а, во-вторых, взрослое население, уже в полной мере погрузившись в финансовый рынок, может более адекватно давать себе оценки исходя из опыта пользования финансовыми услугами.

\section{ЛИТЕРАТУРА}

1. Каликова Д.И. Опыт внедрения курса «Основы финансовой грамотности» / Д.И. Каликова. — Текст: непосредственный // Молодой ученый. - 2018. — № 32 (218). — C. 87-89. — URL: https://moluch.ru/archive/218/52316/ (дата обращения: 24.09.2020).

2. Бокарев А. Повышение уровня финансовой грамотности населения в Российской Федерации // Финансы. 2010. № 9. С. 3-6.

3. Зеленцова А. Повышение финансовой грамотности населения: меж Иванова Т. Повышение финансовой грамотности: обзор международного опыта // Вестн. Волгогр. гос. ун-та. Сер. 3, Экон. Экол. 2012. №1(20). С. 222-229.

4. Зеленцова А., Демидов Д., Блискавка Е. Повышение финансовой грамотности населения: международный опыт и российская практика. М.: ЦИПСиР. 2012. $112 \mathrm{c}$.

5. Ибрагимов К., Продолятченко П. Кадровое обеспечение реализации программ повышения финансовой грамотности населения //ДИСКусСия. 2015. №. 5.

6. Игонина Л. Финансовая система России: анализ структурно-функциональных характеристик //Экономический анализ: теория и практика № 33 (336) 2015.T. 11.C. 14. 
7. Карпунин М. «Свои деньги» - проект по повышению финансовой грамотности населения // Деньги и кредит. 2008. № 2. С. 18-19.

8. Кузина 0. Финансовая грамотность молодежи // Мониторинг общественного мнения. 2009. №4(92).

9. Кузина 0. Мониторинг финансового поведения и доверия населения финансовым институтам, 2012 С. 98-104

10. Национальная доктрина развития образования в России http://sinncom.ru/content/reforma/index5.htm

11. Перечень программ и проектов по финансовой грамотности, действующие в Российской Федерации http://onlinetestpad.com/ru-ru/User/10241/Page/363

( Беляева Олеся Николаевна (003835@pnu.edu.ru), Некрасова Александра Игоревна (010290@pnu.edu.ru).

Журнал «Современная наука: актуальные проблемы теории и практики»

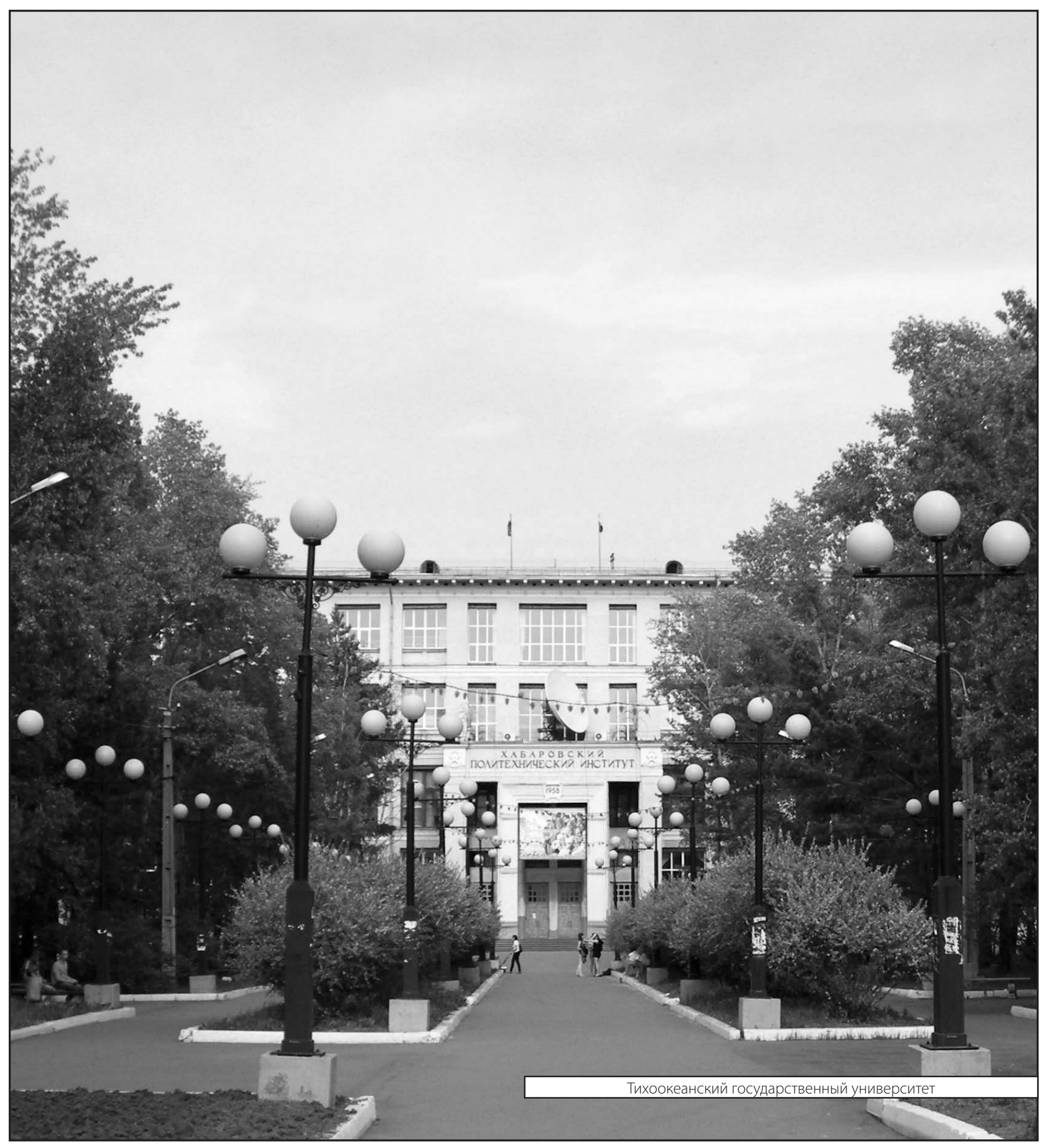

